\title{
Análise da importância do solo para os recicladores da Associação Solidária Força no Braço no município de Restinga Sêca, RS
}

\author{
Analysis of the importance of the soil for recyclers of Associação \\ Solidária Força no Braço in the county Restinga Sêca, RS
}

\author{
Lenice De Carli ', Ricardo Simão Diniz Dalmolin "
}

\begin{abstract}
RESUMO
O presente trabalho foi desenvolvido com os membros de uma associação que efetua a separação de resíduos sólidos, a Associação Solidária Força no Braço de Restinga Sêca, RS, e visou efetuar o repasse de informações sobre a importância e funções que o elemento solo desempenha em uma área que possui como atividade a separação de resíduos sólidos urbanos para a reciclagem, assim como aterros sanitários, apresentando formas de contaminação do solo e da água, especialmente as causadas pelo chorume e demonstrando formas de evitar que a mesma ocorra, foi desenvolvido por meio de debates, apresentação sobre o tema abordado e aplicação de questionário, após a aplicação da atividade houve, pelo grupo, uma sensibilização com relação aos conhecimentos sobre o solo e sua relação com a disposição de resíduos sólidos, assim como sobre cuidados a serem tomados por meio do seu trabalho a fim evitar a sua contaminação.
\end{abstract}

Palavras-chave: Solo; Resíduos sólidos; Educação ambiental.

\section{ABSTRACT}

The present work was developed with the members of a solid waste separation association, the Associação Solidária Força no Braço, and aimed to provide information about the importance and functions that the soil element plays in a The area whose activity is the separation of urban solid waste for recycling, as well as landfills, presenting forms of contamination of soil and water, especially those caused by slurry and demonstrating ways to prevent it from occurring, was developed through debates, presentation on the theme and questionnaire application, after the application of the activity there was, by the group, an awareness about the knowledge about the soil and its relation with the disposal of solid waste, as well as about the care to be taken through of your work in order to avoid its contamination.

Keywords: Soil; Solid waste; Composting; Soil paint.

I Engenheira Florestal, Especialista em Educação Ambiental, UFSM. E-mail: lenicedecarli@hotmail.com. ORCID: https://orcid.org/0000-0002-8787-336X.

" Doutor em Ciência do Solo. Departamento de Solos, UFSM. E-mail: dalmolinrsd@gmail.com. ORCID: https://orcid.org/0000-0002-8834-9869. 


\section{INTRODUÇÃO}

A atual forma de organização da sociedade, em grandes centros urbanos, transformou-os em núcleos consumidores e geradores de enormes quantidades de detritos. Acrescido do fato que a população que está direcionada a viver dentro de padrões de consumo cada vez mais expansivos, acaba por acarretar no aumento da utilização de produtos com menor ciclo de vida e que utilizam embalagens descartáveis. Assim, a atual ordenação social gera uma massiva produção de resíduos e com isso a necessidade de áreas para efetuar a separação, reciclagem, reutilização e a disposição final dos mesmos.

No município de Restinga Sêca, localizado na Depressão Central do estado do Rio Grande do Sul, existe um programa de coleta seletiva por meio do qual é efetuado a separação e encaminhamento para a reciclagem dos resíduos sólidos, urbanos e rurais, do município. Os demais resíduos não passíveis de reciclagem são coletados separadamente e encaminhados a um aterro sanitário, para a disposição final ambientalmente adequada. Quem realiza estas tarefas são os trabalhadores da Associação Solidária Força no Braço (ASFOB) que foi fundada em dezembro de 2015. Estes trabalhadores, e mesmo a sociedade em geral, muitas vezes, não percebem a importância deste trabalho para manutenção equilibrada do ambiente onde vivem.

Segundo Cornieri e Fracalanza, (2010), a partir das atividades humanas são produzidos resíduos sólidos, entretanto boa parte destes não apresentam uma destinação correta e essa disposição gera graves consequências como a proliferação de vetores e doenças, a contaminação de recursos hídricos e do ar, além da degradação do solo. De acordo com Azevedo e Dalmolin (2006), a disposição inadequada dos mesmos pode ocasionar diversas consequências ambientais negativas, como a poluição do solo e da água.

Para a correta disposição dos resíduos, os solos devem conter no mínimo 35\% de argila, com boa drenagem, baixo gradiente textural e localizados em relevo 
preferencialmente plano e com baixo risco de inundação (Pedron, et. al., 2004; Kämpf, et. al., 2008).

Assim, quando busca-se espaços passíveis de efetuar a separação e deposição de resíduos sólidos, a cautela na escolha do local e do solo é um fator para o qual deve-se refletir com seriedade. O solo apresenta um importante papel na inertização dos resíduos depositados sobre ele, o que será afetado em maior ou menor escala por suas propriedades físico, químico e biológicas e, deste modo, irá influenciar na depuração e retenção dos compostos tóxicos liberados pelos materiais, (Azevedo e Dalmolin, 2006).

Contextualizando o solo com a sociedade e os resíduos sólidos produzidos por ela, observa-se que as distintas percepções e sensibilizações, relacionadas ao cotidiano das pessoas e aos elementos que compreendem o seu ambiente, são diferenciadas e sugerem o modo como os indivíduos agem e reagem, frente as ações, sobre o meio em que habitam (Muggler, et. al. 2006; Campos, et. al., 2018). Conforme Mendes et. al. (2019), alguns destes elementos são familiares e compreendidos ao passo que outros ocorrem despercebidos, pois o ambiente nada mais é que seus vários componentes funcionando de modo integrado e, logo, quando se afeta uma parte afeta-se o todo. O solo é um dos elementos cuja importância é pouco notada, não sendo considerado pelo essencial papel que desempenha na manutenção da sociedade e da biodiversidade.

Assim, a disseminação de informações do solo para grupos-alvo faz parte do processo de entendimento sobre a importância do mesmo, e trata-se de uma das faces da Educação Ambiental, que busca uma compreensão de sustentabilidade entre as relações homem e natureza e refere-se, sobretudo, à busca por um convívio harmonioso entre o homem e o meio ambiente, natural ou não, transformando, assim, o potencial das pessoas de entenderem e modificarem o meio ao seu redor, (Gordin, et. al., 2012). Os esforços de conscientização iniciados por instituições 
científicas são cruciais para a educação de determinados grupos de interesse, sendo que o sucesso para perpetuá-los, para o público em geral, requer mais do que uma transferência de conhecimento técnico científico e envolvem outras formas de ensinar como fatores sensoriais, emocionais, corporais, estéticos, conhecimento popular, entre outras, como um processo de formação dinâmico e participativo. Esta forma de repasse alternativo de informações sobre o solo também é necessária para comunicar a urgência dos objetivos de proteção do solo, para a busca por uma "consciência pedológica" e para criar laços duradouros entre os membros da sociedade e o ambiente (Toland, 2018; Carvalho e Barcellos, 2017).

Ações que visem aumentar as informações a respeito do valor que o elemento solo possui para as pessoas que trabalham em áreas de separação de resíduos sólidos são de suma importância, em relação às precauções e cuidados, ocasionando mudanças de hábitos e atitudes no seu dia a dia que podem contribuir para a preservação do equilíbrio do próprio solo, da água e consequentemente do ambiente de trabalho.

Assim, este trabalho teve como objetivo, ações coletivas sobre a importância e funções do solo incluindo diferentes atores da comunidade, em um local que possui como atividade a separação de resíduos sólidos urbanos para a reciclagem.

\section{METODOLOGIA}

O Método de Abordagem deste trabalho foi baseado em Estudo de Caso, por meio da sistematização de dados de natureza qualitativa que foram coletados através da exposição, do repasse e da coleta de informações efetuado com os membros integrantes da ASFOB. Este método foi escolhido, porque enfatiza entendimentos contextuais, buscando a compreensão da dinâmica do contexto real (Freitas e Jabbour, 2011). 
Foi usado como Método de Procedimento o Método Qualitativo, uma vez que este possui a preocupação com a significação dos processos sociais, de compreender o significado e características de um determinado grupo social, de forma interativa e intercomunicativa criando um processo de conhecimento circular (Gerhardt e Silveira, 2009; Oliveira, et. al., 2017).

Foi abordado questões sobre a importância que o solo apresenta para os membros da ASFOB e para o seu trabalho, de modo a auxiliar na compreensão dos processos dinâmicos vivenciados em sua rotina, como o valor das relações que estabelecem com o elemento a ser estudado e como o cuidado com o solo pode proporcionar mudanças positivas para o grupo.

Foram utilizadas práticas interpretativas que proporcionaram aos participantes distintas representações do assunto abordado, com a utilização de oficina e da técnica de pesquisa por entrevista, uma vez que esta permite a captação das informações dos participantes da ASFOB a respeito de seus entendimentos e opiniões sobre a importância do solo.

As entrevistas foram realizadas por meio de questionários semiestruturados, pois partiu-se do pressuposto que nem todos os participantes compreendem da mesma forma as questões levantadas, fornecendo uma maior possibilidade de entendimento destas, que são objeto de estudo, assim como a possibilidade do surgimento de novos assuntos não previstos pelo pesquisador (Oliveira, 2008).

O trabalho foi realizado na central de triagem do município de Restinga Sêca, sendo que foi feito a apresentação do projeto, a entrega dos termos de compromisso e a entrega do questionário, a respeito do conteúdo do projeto.

Inicialmente foi realizada a apresentação do projeto e de seus objetivos para os membros da Associação Força no Braço a fim de repassar informações, sanar questionamentos, além de fazer uma socialização com os participantes. Foi lido o termo de consentimento para o grupo, a fim de esclarecer dúvidas, também foi 
deixada cópias do mesmo para que os participantes tivessem acesso às informações e contatos presentes no mesmo.

Na sequência foi proposto para o grupo um questionário, que foi aplicado antes da realização da atividade proposta e, novamente, após seu término, a fim de avaliar suas percepções sobre o solo, seus usos e suas relações com o seu ambiente de trabalho. As questões abordaram os conhecimentos dos participantes sobre o solo, sobre seus usos e a sua relação com os resíduos sólidos e por último sobre o trabalho que eles realizam na Associação. Os participantes não precisaram se identificar e foram informados que poderiam se sentir à vontade para colocar o que pensavam ou sabiam sobre o solo.

$\mathrm{Na}$ etapa seguinte fez-se uma roda de conversa com os membros do grupo sobre suas opiniões e conhecimentos do elemento solo. Foi realizada uma apresentação, em forma de slides, junto de um diálogo relativo à importância, funções, particularidades como a composição, relação do solo com a água, a vegetação, com as áreas urbanas e com o dia a dia.

Fez-se uma abordagem especial para áreas de separação e depósito de resíduos urbanos e aterros, considerando a contaminação pelo chorume, e como a composição do solo influência neste processo. Também foi abordado o funcionamento de um aterro sanitário, visto que os materiais que os mesmos não podem encaminhar para a reciclagem são enviados para lá, e deste modo seu trabalho influência diretamente na qualidade e quantidade dos resíduos que são enviados.

\section{RESULTADOS E DISCUSSÃO}

Os participantes aceitaram as atividades propostas mostrando-se, em todos os momentos, receptivos, atentos e participativos. 
Em uma avaliação generalizada, as atividades desenvolvidas se mostraram eficazes, pois os membros da associação conseguiram entender e correlacionar as suas atividades cotidianas e os seus serviços com a importância que o solo possui em centrais de triagem e em aterros sanitários e a relação que estes possuem com a contaminação das águas e do próprio solo. Além disso, como a degradação dos resíduos influencia estes locais e a vida das pessoas das proximidades. De acordo com Fiuza e Trevisan, (2016) é indispensável que haja o conhecimento desta realidade local, que é vivenciada pelos membros da associação, para a formação de uma postura ambiental que visa à mudança de hábitos.

As ações desenvolvidas auxiliaram na assimilação de conceitos a respeito de solos, que inicialmente eram confundidos pelo grupo, de modo que, ao final, os participantes se sentiam mais seguros para tratar do assunto e para correlacioná-lo com outros elementos e com seu cotidiano, seu trabalho e o meio urbano e não principalmente com o meio rural e a produção agrícola, como ocorria anteriormente. Isto vai ao encontro das ideias de Buss e Moreto, (2019), uma vez que o desenvolvimento de práticas de educação ambiental em solos auxiliou na cons trução de mudanças na percepção dos participantes e consequentemente mudanças de atitudes buscando um comprometimento com o espaço onde estão inseridos e também os tornando educadores ambientais da comunidade.

As atividades também dialogam conforme Mugler, et. al. (2006), pois funcionaram como uma ponte para ampliar a compreensão dos participantes sobre o solo como um componente fundamental do meio ambiente e auxiliaram na sensibilização do grupo para a importância da conservação, assim como da atual degradação do solo em suas distintas formas e também para popularizar entre eles conhecimentos acerca do assunto. Este conhecimento contribui para a criação de um elo que integra seus saberes e vivências sobre solos com uma sistemática maior e 
dinâmica em virtude da formação de uma consciência ambiental, (Carvalho e Barcellos, 2017).

A apresentação inicial foi importante para o grupo, pois os auxiliou a entender que seu trabalho não pode ser realizado em qualquer local, que é necessário uma impermeabilização do solo onde é feita a separação dos resíduos a fim de evitar contaminação. Em todos os momentos mostraram-se interessados pelo assunto proposto e, embora no começo, estivessem retraídos, e com vergonha de fazer comentários e questionamentos, conforme o assunto e os slides foram evoluindo começaram a fazer perguntas e comentários. Em alguns momentos inclusive antecipando assuntos que seriam abordados na sequência.

Também se interessaram pela questão da contaminação do lençol freático pelo chorume e compreenderam que não podem ser instalados em locais próximos a cursos d'água, e como isso influência processos como o licenciamento ambiental, devido ao risco de contaminação do lençol freático. As pessoas mais antigas na associação ligaram este problema ao antigo local onde trabalhavam que não possuía um isolamento adequado para todos os resíduos que chegavam e, considerando que na época não havia a coleta seletiva instalada no município, recebiam muitos resíduos orgânicos misturados com os seletivos.

Para a maioria das pessoas presentes na associação este assunto não havia sido abordado e explicado de forma direta e aberta até então, sendo algo desconhecido, e serviu para consolidar seus conhecimentos sobre como o elemento solo possui uma importância vital para seu serviço e como o mesmo, quando realizado de forma correta e seguindo procedimentos adequados, pode contribuir para um cenário de preservação dos recursos naturais.

Um total de 17 questionários foram respondidos, antes da aplicação da atividade inicial. 
Na primeira parte, $18 \%$ dos participantes não souberam afirmar o que é o elemento solo e $77 \%$ afirmaram que sabiam. Apenas $5 \%$ não respondeu. Nesta questão houve respostas como "o solo é a terra onde pisamos", "o solo é a nossa riqueza e sem o solo não há produção de alimentos", "sim é muito importante para as pessoas, se cuidar e tratar da terra vai ser sempre bem cultivada, pois sem ela que seria de todos nós".

Ainda, sobre a importância do solo nas vidas deles e nos seus trabalhos, as respostas foram variadas, desde os que não souberam responder o porquê o solo é importante em sua vivência, até os que afirmaram que é importante para a produção de alimentos, para o meio ambiente, a vida e nossa existência, entretanto, todos afirmaram que o mesmo é importante (Figura 1), o que demonstra que possuem uma consciência da importância que o solo possui para a nossa sociedade, como exemplos "dependemos do solo para basicamente tudo, moramos, produzimos, trabalhamos, morremos, enfim ele faz parte de nós do começo ao fim do nosso tempo", "pois sem o solo tudo seria devastador, ele é pra plantar, germinar, etc.", "porque o lugar que trabalho é em cima do solo", "porque se não iriamos estar flutuando ao invés de caminhar" e "porque do solo sai praticamente todos os materiais que reciclamos".

Na parte do questionário relacionada aos usos do solo e a sua relação com os resíduos sólidos, nas questões sobre a contaminação do solo e da água com lixo 5\% dos participantes responderam que não sabiam, 5\% deixaram a questão em branco e os outros $90 \%$ responderam de forma positiva, demonstrando possuir conhecimentos acerca do assunto e consciência que se o lixo for depositado de forma inadequada no solo pode causar a contaminação do mesmo e das águas. Dentre suas respostas estão "sim porque muito material tóxico se mistura no meio ambiente e porque acabamos tomando esta água contaminada", "esse lixo se decompõe liberando o chorume que contamina o solo e o gás metano que prejudica a camada de ozônio e por consequência toda a vida do planeta", "porque tem muitos resíduos 
que contamina o solo e leva séculos para desmanchar", "porque a terra fica imprópria para o plantio e o chorume contamina os lençóis de água que existem embaixo do solo", "sim contamina não só o solo como o ar".

Já na questão que abordava se os mesmos conheciam algum aterro sanitário e sua relação com o solo, $41 \%$ dos participantes deixaram esta parte da questão em branco ou responderam que não sabiam, $35 \%$ nunca tinham visto um aterro, $24 \%$ respondeu que conhecia um aterro. Contudo $71 \%$ dos participantes afirmaram que, antes da construção de um aterro deve ser feitos estudos pra evitar a contaminação do solo, o que leva a deduzir que é provável que alguns participantes não quiseram ou não lembraram de responder se já tinham visto um aterro, pois mantiveram seu foco na segunda parte da questão. Dentre suas respostas sobre a necessidade de estudar o solo estão "porque vai muita coisa que não deveria ir no solo sanitário", "para tomar algumas providências para não poluir o solo", "não só estudar o solo, mas também o entorno dele para verificar se tem pessoas, animais e até mesmo certas vegetações".

A questão relacionada ao uso do solo e se o mesmo pode ser perdido em decorrência disso $12 \%$ dos participantes não responderam, $29 \%$ responderam que o solo não seria perdido, mas necessita ser cuidado, como "não acho que o solo pode ser perdido é só a população ter higiene e manter limpo", $6 \%$ responderam que não sabiam e 53\% que sim, entre suas respostas "pode ser perdido com a própria queima do lixo acaba estragando o solo", "pode ser perdido sim porque a partir do momento que ele recebe matéria que não é produzida por ele, ele não é mais um solo puro, dependendo do material depositado não serve para mais nada", "sim ele pode ser perdido pois ele é vivo como nós, se não for tratado com respeito pode morrer".

$\mathrm{Na}$ última questão foi questionado se os participantes consideram seu trabalho na Associação Força no Braço importante para o município onde moram. 12\% não responderam e $88 \%$ consideram que sim, com respostas variando desde a deixar a 
cidade mais limpa, a geração de emprego e renda, ajudar a comunidade, preservar o meio ambiente e auxiliar a comunidade, como "eu acredito que sim, pois eu faço meu trabalho com muita dedicação e acredito que o pouco que faço pode fazer a diferença para meus filhos e netos e espero deixar o exemplo para eles", "eu acho que se não for nós que seria do nosso município além de nos dar trabalho e ganho" e "pois nosso trabalho ajuda a conscientizar a população do município a importância da destinação correta deste material pois ele gera renda e contribui com todo ecossistema existente em nosso município. Afinal somos responsáveis por tudo que fazemos, produzimos, geramos, amamos e até por aquilo que não queremos mais".

As respostas do grupo, para o questionário que foi aplicado antes da atividade são apresentadas na figura 1. Por meio de sua análise é perceptível que eles demonstraram possuir uma boa noção do que é o elemento solo e de sua importância para a realização de seu trabalho.

\section{Figura 1 - Conhecimentos do grupo sobre solos}

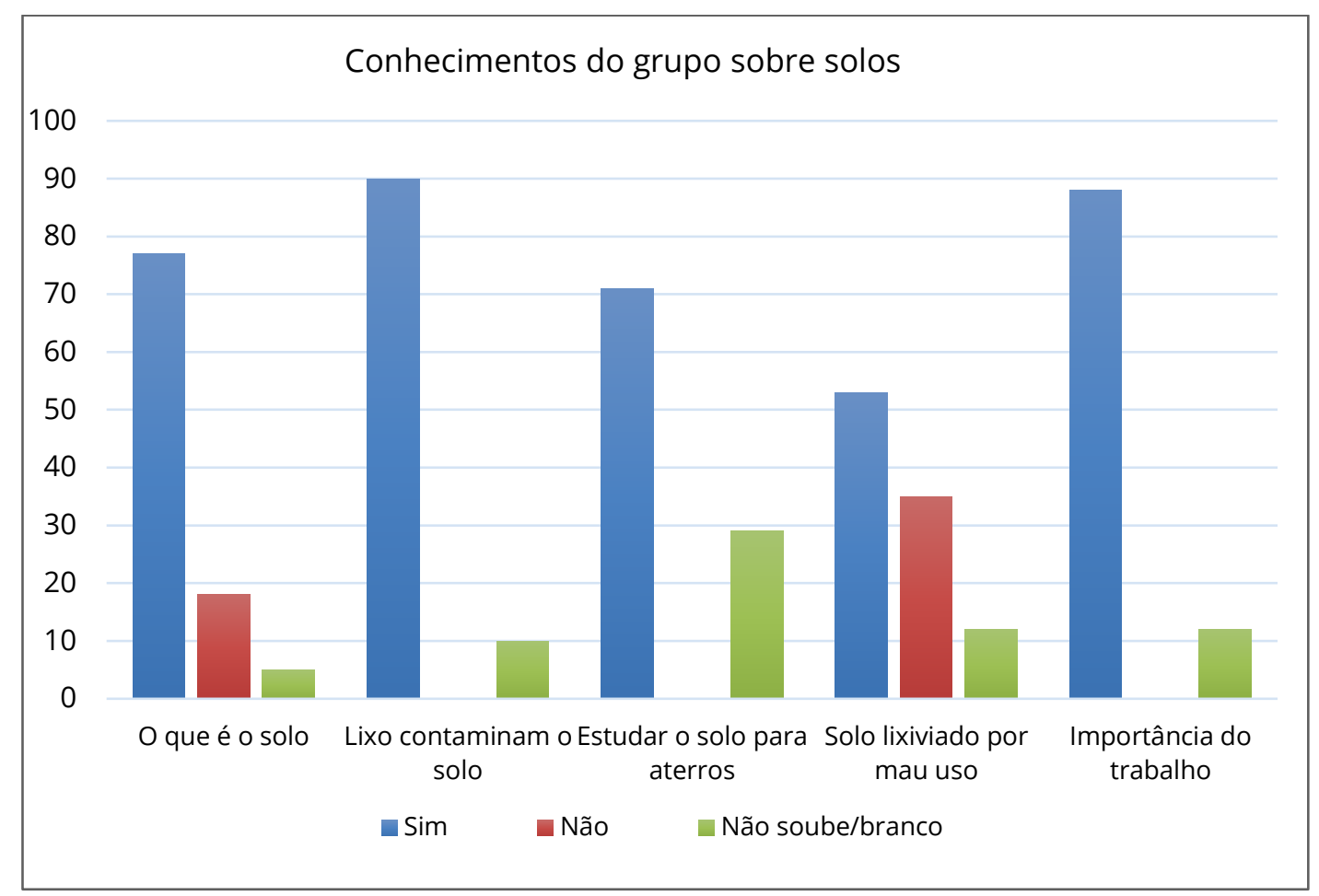

Fonte: Autora. 
Após analisar as respostas do questionário é possível observar que a partir da sexta questão, sobre o solo em aterros sanitários houve uma taxa maior de questões com respostas nulas. Tal fato se deve, pois dois questionários não foram respondidos integralmente na segunda parte, provavelmente por distração dos participantes. Além disso, foi possível perceber que questões onde havia mais de uma pergunta alguns membros acabavam por se ater em explicações de uma e não respondiam integralmente a mesma.

Após o desenvolvimento da atividade proposta foi repassado para os membros da Associação responderem novamente ao questionário inicial do projeto, nesta fase 16 membros participaram, suas colocações se encontram abaixo.

Com relação à primeira pergunta $6 \%$ dos participantes deixaram a questão em branco, os outros $94 \%$ dos membros responderam que sim, sabiam o que era o elemento solo, porém nem todos explicaram o que é isso. Provavelmente por já terem respondido a esta questão, no questionário anterior. Porém houve respostas como "ele é um recurso natural, é um meio de sobrevivência dos humanos e dos animais", “porque é do solo que as plantas retiram os nutrientes necessários e por sua vez nós seres humanos consumimos esses alimentos", "porque sem eles nós não vivemos" e "pois sem o solo não temos nada".

$\mathrm{Na}$ questão relacionada à contaminação do solo, novamente todos os participantes afirmaram que sim o lixo pode contaminar o solo e a água que tomamos, "contamina e o lixo não deixa oxigênio na água", "sim, pois o solo absorve todos os componentes incluindo os que não fazem bem para a saúde", "depende do lixo contamina sim, ainda mais aqueles que demora para decompor", "claro, até porque quando chove a terra absorve a água que acaba caindo nas barragens e depois desce pelo tratamento da Corsan".

Na pergunta sobre aterros sanitários 19\% dos participantes responderam que não sabiam ou deixaram a questão em branco, $62 \%$ afirmaram que nunca viram um 
aterro "nunca vi aterro sanitário" e 19\% afirmaram que já tinham visto. Com relação ao estudo do solo antes de efetuar um $44 \%$ afirmou que deve ser feitos estudos do solo nestes locais, como "sim, deveria sim ser estudado para poder avaliar a situação e por fim poder mostrar para as pessoas os vários tipos de resíduos tóxicos que contaminam o solo e prejudicam a saúde" e "devemos sim estudar, pois tem que tomar tem que tomar todas providências para não poluir o solo" e os outros $56 \%$ não souberam responder ou não comentaram sobre a questão do solo, possivelmente por não terem participado da primeira oficina ou por já terem respondido a mesma pergunta anteriormente.

$\mathrm{Na}$ questão sobre perda de solo por mau uso, 6\% dos participantes não responderam a questão, $6 \%$ afirmaram que o solo não seria perdido e os outros $88 \%$ responderam que achavam que o solo pode ser perdido sem cuidados, "sim porque o solo também tem vida", "sim pode ser perdido mas se cuidarmos podemos ajudar" e "com o tempo pode ser perdido sim, pois assim diminui a produção dos alimentos", assim é perceptível, por meio das respostas, que após as conversas com o grupo houve uma sensibilização e um aporte de conhecimentos quanto ao elemento solo.

Na última questão $6 \%$ dos membros não responderam a questão e os outros 94\% responderam que sim, consideram seu trabalho importante para o município por meio de respostas como "sim porque não fica lixo na cidade e nem nas vias, rios ou lagos", "sim com certeza pois é uma maneira de incentivar a população de qual a melhor forma de separar seu material de recicláveis e orgânico, assim diminuindo também a sujeira nas ruas", "de grande importância sim com o nosso trabalho mantemos a cidade e a nossa região limpa além de nos trazer empregos e gerar nosso salário", " sim porque ensina que o lixo é muito importante e não larga nos cantos e nem nos rios". 
Após o encerramento das atividades foi perceptível algumas mudanças em suas respostas enquanto grupo, conforme expresso na figura 2, que apresenta as colocações do grupo no segundo momento de aplicação do questionário.

\section{Figura 2 - Conhecimentos do grupo sobre solos na segunda parte do questionário}

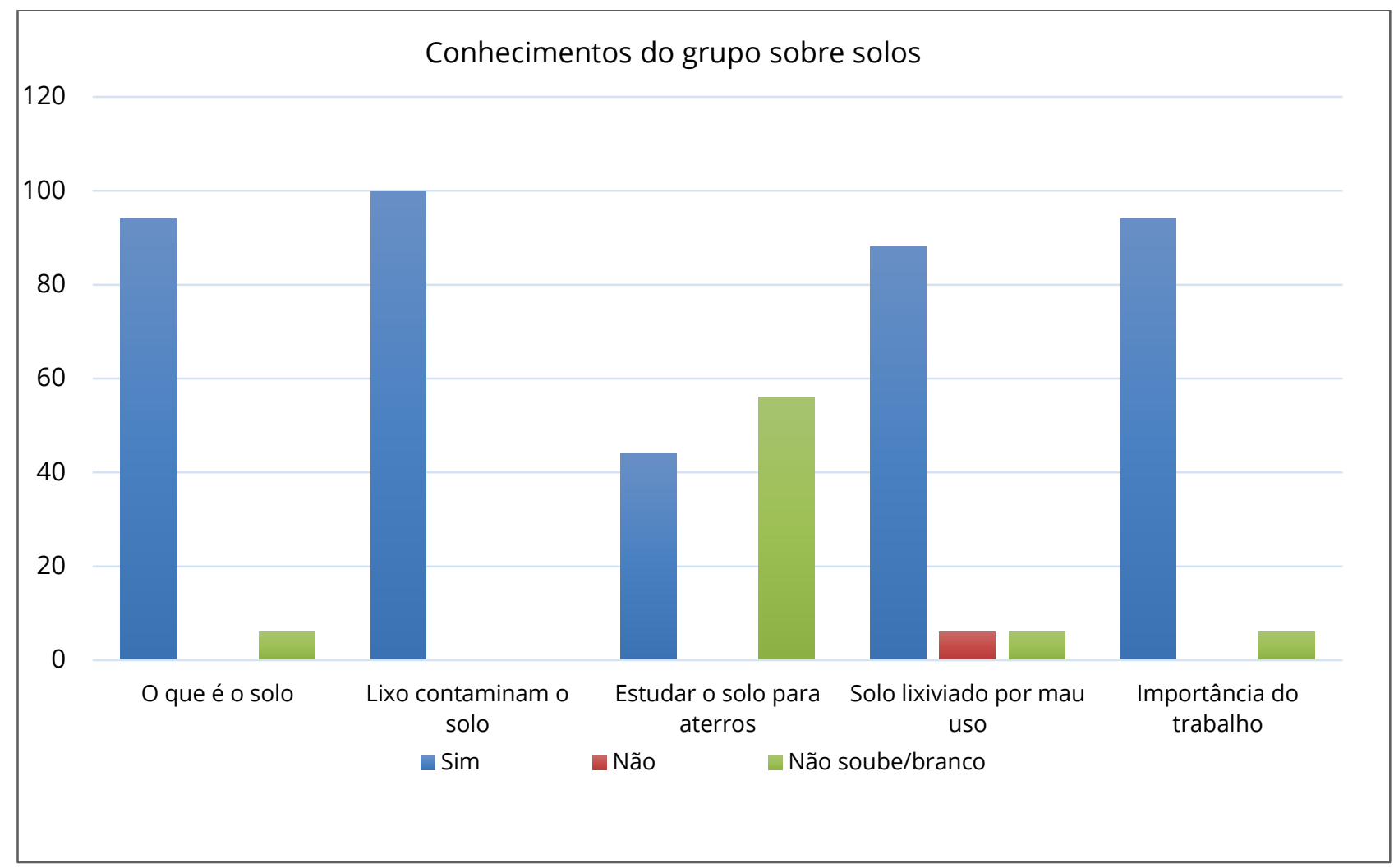

Fonte: Autora.

Por meio da aplicação do questionário e das conversas com o grupo observouse que eles possuíam muitos conhecimentos relativos aos resíduos sólidos, até mesmo sobre a sua composição e como sua decomposição afeta o meio ambiente. Também demonstraram uma boa noção sobre como o seu trabalho, quando não realizado de uma forma adequada, pode contaminar a água e o solo.

Apesar de haver uma variação nas respostas é perceptível que o grupo como um todo compreendeu melhor o que é o elemento solo, assim como generalizaram entre eles as ideias de que resíduos sólidos dispostos inadequadamente contaminam 
o solo e a água. Com relação ao estudo do solo em aterros sanitários houve membros que não responderam a questão integralmente. Responderam somente que não tinham visto um aterro e o restante deixou em branco. Tal fato pode ter ocorrido por distração ou por estas pessoas não terem participado da primeira oficina.

Também foi possível observar, conforme a figura 3, que apresenta a comparação das respostas dos questionários aplicados antes e após o desenvolvimento da atividade proposta, e, também, por meio de conversas com o grupo, que houve um aporte de conhecimentos mais técnicos, sobre a formação do solo e como ele pode influenciar as atividades em centrais de triagem e em aterros sanitários. Estas ações serviram para sensibilizar os membros do grupo sobre a importância de ter certos cuidados na realização do seu trabalho e na separação e reciclagem dos materiais.

Figura 3 - Comparativo das respostas dos questionários respondidos pelo grupo antes e depois da aplicação da atividade proposta

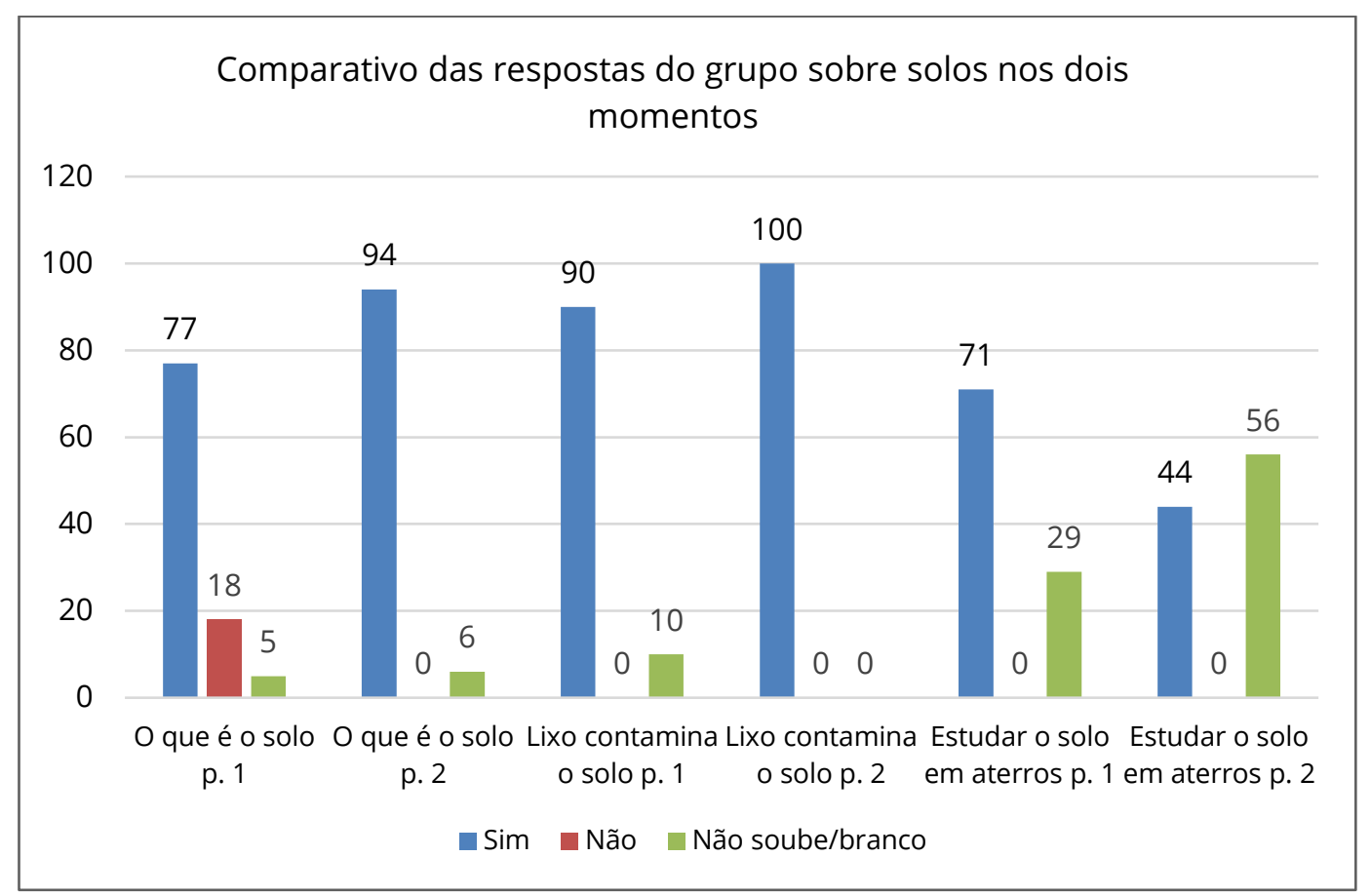

Fonte: Autora. 
É possível perceber, ao analisar as respostas da figura 4, que houve uma sensibilização dos membros da associação quanto ao fato que o solo pode ser perdido e não for cuidado.

Figura 4 - Segunda parte do comparativo das respostas dos questionários respondidos pelo grupo antes e depois da aplicação da atividade proposta

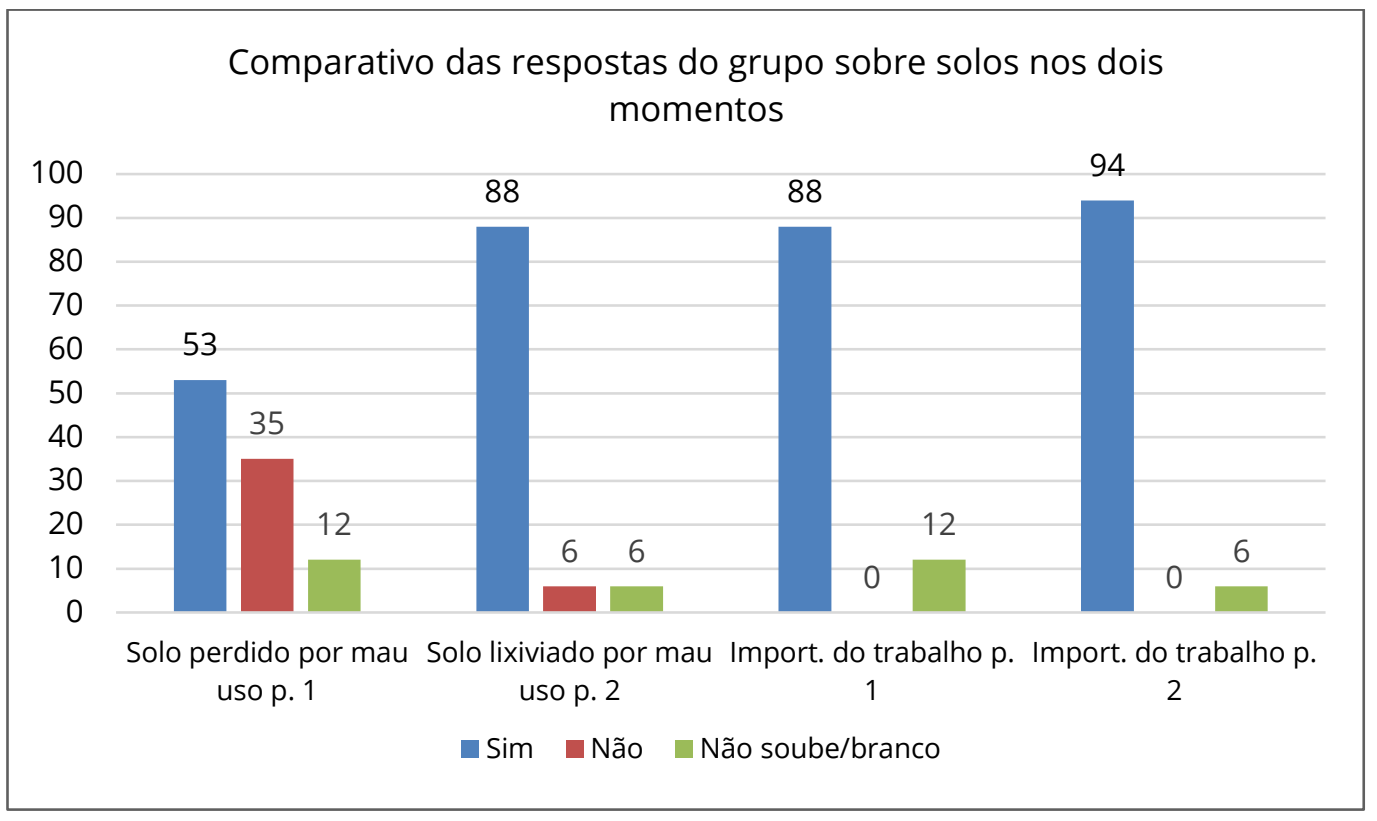

Fonte: Autora.

Ao abordar-se, durante as falas, o tema solo de modo prático, vinculado com as experiências cotidianas dos participantes e de maneira interdisciplinar proporcionouse um vínculo com as vivências do grupo, assim como, com assuntos de ordem econômica, cultura e social. Isto leva-os, conforme também relatado por Mendes et. al. (2019), a construir uma visão mais abrangente do assunto e uma aquisição de conhecimentos como parte de sua realidade, fato que pode ser percebido através da interação do grupo no momento da apresentação.

No tocante a importância que seu trabalho possui para o município houve um aumento nas respostas positivas e muito embora na primeira parte dos membros deixassem a parte de trás do questionário em branco, na segunda vez que o 
questionário foi aplicado, embora ainda apontassem a questão da diminuição dos resíduos no município e de sua fonte de trabalho e renda, suas respostas estavam mais complexas, como por exemplo, "pois é uma maneira de incentivar a população de qual a melhor forma de separar seu material de reciclável e orgânico... diminuindo a poluição, e diminuindo também a sujeira das ruas" e "sim, porque se esse material estivesse no solo poluiria totalmente o solo".

\section{CONCLUSÕES}

Houve um aporte de conhecimento por parte do grupo na relação solo e separação de resíduos sólidos e aterros sanitários, especialmente no que concerne a contaminação por chorume. Também se constatou que houve um aporte de conhecimento sobre cuidados a serem tomados, por meio do seu trabalho, buscando evitar a contaminação do solo, da água e do ar e assim preservar o meio ambiente para a atual e futuras gerações.

As ações desenvolvidas auxiliou na sensibilização do grupo em relação à importância que o solo possui para o seu trabalho, auxiliando-os a adquirirem conhecimentos novos. Observou-se que os conhecimentos adquiridos estão sendo repassados para a comunidade por meio de projetos particulares desenvolvidos pela ASFOB.

\section{Referências Bibliográficas}

Azevedo, A. C. De e Dalmolin, R. S. D. Solos e o Ambiente: uma introdução. 2 ed. Santa Maria, RS: Gráfica e Editora Pallotti, 100p., 2006.

Buss, A. e Moreto, C. A prática da compostagem como instrumento no ensino de conteúdos e na Educação Ambiental Crítica. Revista Monografias Ambientais (REMOA), Santa Maria v.18, e6, p. 01-10, 2019. Disponível em: https://periodicos.ufsm.br/remoa/article/view/39699/html. 
Campos, A. E. R., et. al. Percepção Ambiental e Estudantes de Enfermagem. Revista Monografias Ambientais (REMOA), Santa Maria v.17, e10, p. 1-5, 2018. Disponível em: https://periodicos.ufsm.br/remoa/article/view/35026/pdf.

Carvalho, N. L. de e Barcellos, A. L. de. Educação ambiental: importância na preservação dos solos e da água. Revista Monografias Ambientais (REMOA), Santa Maria, v. 16 n. 2 maiagos. 2017, $\quad$ p. $39 \quad$ - $51 . \quad$ Disponível em: https://periodicos.ufsm.br/remoa/article/view/30067/pdf.

Cornieri, M. G. e Fracalanza, A. P. Desafios do lixo em nossa sociedade. Revista Brasileira de Ciências Ambientais, Rio de Janeiro, $\mathrm{n}^{\circ} 16$ - junho/2010. Disponível em: file://C:/Users/Lenice/Desktop/389-Texto\%20do\%20artigo-1419-1-10-20190718.pdf.

Fiuza, M. N. e Trevisan, M. L. Educação ambiental: Jacuizinho/RS - conhecer, diagnosticar para preservar! Revista Monografias Ambientais (REMOA), Santa Maria, v. 15, n.1, jan-abr. 2016, p.347-368. Disponível em: https://periodicos.ufsm.br/remoa/article/view/19973/pdf.

Freitas, W. R. S. E Jabbour, C. J. C. Utilizando Estudo de Caso(s) como estratégia de pesquisa qualitativa: boas práticas e sugestões. Estudo \& Debate, Lajeado, v. 18, n. 2, p. 07-22, 2011.

Gerhardt, T. E. E Silveira, D. T., Métodos de pesquisa. 1 ed. Porto Alegre, RS: Editora da UFRGS, 2009.

Gordin, C. R. B., et. al. Inserindo o solo na educação ambiental: uma experiência no CentroOeste. Revista Agrarian, Dourados, v.6, n.19, p.97-106, 2013. Disponível em: http://ojs.ufgd.edu.br/index.php/agrarian/article/view/1653/1383.

Kämpf, N., et. al. Metodologia para classificação de solos quanto à resistência a impactos ambientais decorrentes da disposição final de resíduos. Fepam em Revista, Porto Alegre, v.2, n.1, p.11-17, jan./dez. 2008. Disponível em: http://www.fepam.rs.gov.br/FepamEmRevista/downloads/Revista_2008_BAIXA.pdf\#page $=11$.

Mendes, T. A., et. al. Uso de ferramentas interativas de ensino para a Educação em Solos: um estudo de caso em escolas municipais de Pato Branco - PR. Rev. Eletrônica Mestr. Educ. Ambient. Rio Grande, v. 36, n. 1, p. 163-184, jan./abr. 2019. Disponível em: https://periodicos.furg.br/remea/article/view/8713/5816.

Mugller, C. C., et. al. Educação em solos: princípios, teoria e métodos. Rev. Bras. Ciênc. Solo. Viçosa, vol.30, $n^{\circ} .4$, p. 733-740. jul.-ago., 2006. Disponível em: http://www.scielo.br/scielo.php?script=sci_arttext\&pid=S0100-06832006000400014. 
Oliveira, C. L. de. Um apanhado teórico-conceitual sobre a pesquisa qualitativa: tipos, técnicas e características. Revista Travessias, v.02, n.03, 2008. Disponível em: http://erevista.unioeste.br/index.php/travessias/article/view/3122/2459.

Oliveira, N. M. de, et. al. Técnicas de pesquisa qualitativa: uma abordagem Conceitual. Ciências Sociais Aplicadas em Revista, v.17, n.32, p.87-110, 2017. Disponível em: https://www.researchgate.net/publication/318886166_Tecnicas_de_Pesquisa_Qualitativa_ uma_abordagem_conceitual.

Pedron, F. de A., et. al. Solos urbanos. Ciência Rural, Santa Maria, v. 34, n. 05, p. 1647-1653, set.-out., 2004. Disponível em: http://www.scielo.br/pdf/cr/v34n5/a53v34n5.pdf.

Toland, A. Which Public? Audiences of soil communication from an arts and humanities perspective. (2018). In: 21 WCSS: Proceedings of the 21st World Congress of Soil Science; 2018, August 12-17; Rio de Janeiro, Brazil [e-book]. Anais... Viçosa, MG: SBCS; 2019. Vol. I. p. 30 